\title{
Metabolic Profiling of Wastes from Raw and Ripe Mango Seeds to Comprehend Its Beneficial Medicinal and Cosmetic Properties for Commercialization
}

\author{
Jagruti Tank \\ Bijasu Agri Research Laboratory LLP, Sr. No. 37, old no. 33, \\ Kondhawa Industrial Estate, Khadi Machine Chowk, \\ Kondhawa, Pune-411048, India \\ Dattatraya U. Ukale \\ Department of Chemistry, Central Instrumentation Facility, \\ Savitribai Phule Pune University, Ganeshkhind Road, \\ Pune - 411007, India
}

Vidhyashri Mapare, Bela Dhamangaonkar \& Nivedita Cukkemane

Bijasu Agri Research Laboratory LLP, Sr. No. 37, old no. 33,

Kondhawa Industrial Estate, Khadi Machine Chowk,

Kondhawa, Pune-411048, India

Abhishek A. Cukkemane (corresponding author)

Bijasu Agri Research Laboratory LLP, Sr. No. 37, old no. 33,

Kondhawa Industrial Estate, Khadi Machine Chowk,

Kondhawa, Pune-411048, India

Tel: 91-8888-23-0077 Email: director@bijasu.org

Received: October 31, 2016 Accepted: November 25, 2016 Published: December 27, 2016

doi:10.5296/jas.v5i1.10234

URL: http://dx.doi.org/10.5296/jas.v5i1.10234 


\section{Abstract}

Mango (Mangifera indica) is a widely popular tropical fruit. When ripe, it is consumed either as fruit or juice, while raw mangoes are used in pickles, juice and curries. Apart from these, the seed kernels of ripe mangoes are in great demand by cosmetic and confectionary industries, while those from raw mangoes are used for medicinal purposes in traditional households of India. Although, the seed kernels have been used for various beneficial purposes, the inconsumable mango seed largely poses as a waste and biological pollutant. Therefore, it is pertinent to highlight the detailed composition and benefits of butter from various stages of mango kernel to highlight its commercial relevance. By using a combination of nuclear magnetic resonance spectroscopy and gas chromatography-mass spectroscopy based metabolic profiling, we studied the biochemical composition of different stages of mango kernel extract. We observed predominance of various types of fatty acids in all types of mango kernel with the ripe version showing the largest amount. The unripe versions though showed presences of a variety of aromats and antioxidants albeit at lower amounts. Our findings highlight that the unripe mango kernel extracts contains various aromats that have antimicrobial effects. India produces up to 23 million tonnes of mangoes every year and it has been estimated that it can produce up to 2.3 million tonnes of mango butter. Along with the fatty acids, these antimicrobials can be extracted as butter for commercial relevance thereby adding value to the seed kernel waste which otherwise pose as bio-pollutant.

Keywords: Mango seed kernel, Nuclear Magnetic Resonance spectroscopy, Gas chromatography, mass spectroscopy, metabolic profile

\section{Introduction}

Mango (Mangifera indica) is a tropical fruit that is widely grown in India and other warmer regions like South Africa, Pakistan, Bangladesh, Mexico, and few more countries. India accounts for more than 54\% of the global production of mango estimated to be around 17-23 million tonnes Kg annually (FAO 2002; Ministry of Agriculture, Government of India (2013); Srikanth et al. 2015). The fruit comprises of a fleshy region and a stone, which consists of a hard shell and the kernel within. The fruit is a global delicacy widely consumed throughout the world. Refreshment drinks such as juices and milk-shakes are also very popular around the world. Due to its wide spread popularity, a lot of biochemical data (Gil et al., 2000; Khakimov et al., 2016) is available on the composition of kernel, especially its fatty acid (FA) content (Gunstone, 2007; Shobana and Rajalakshmi 2010). In comparison to its ripe counterpart, raw mango is widely used for culinary purposes, especially in India, where it is a major component of the pickling and chutney industries. Apart from this it is used as refreshment drink known as kairi panna in western part of the nation and the seed is used in South Indian curries called as thogayal and kozhambu. The seeds of mango are also used in traditional Indian medicine to treat gastric related problems. In fact, scientific reports have shown that extract of ripe mango kernels have antimicrobial activity (Alok et al., 2013; UNIDO) and can be used as food preservative (Pereira et al., 2011) as well. It is thus important to understand the composition of the various stages of kernel to realize its flavouring and pharmacological properties (Shobana and Rajalakshmi 2010; Leake, 1974). 
Due to the overwhelming size of the industry (Ministry of Agriculture, Government of India (2013)) seeds from both raw and ripe mango pose a major environmental pollution problem. In many food industries, these wastes are dumped on sites nearby, where they accumulate and decay, producing foul odour. Similarly, biological degradation of mango stones is also a tedious process as it can take up to 8 months. It is thus important to identify and generate awareness of the different components present in mango seed kernels that can be used for various commercial purposes, thereby effectively minimizing pollution. The benefits of ripe mango kernel (RiMK) is known (though largely restricted to FA), and is used in cosmetic and food industries as a substitute to cocoa and shea butter (Kaphueakngam et al, 2009; Kittiphoom and Sutasinee, 2013).

Likewise, it is necessary to identify in details the biomolecules in raw mango kernel (RaMK) and the intermediary raw mango kernel (IrMK) that can benefit health, food, medicine and cosmetic industries. It has been estimated that India has a potential of extracting many million metric tonnes of Mango butter (FAO 2002).

In recent years, biophysical techniques such as Nuclear Magnetic Resonance (NMR) spectroscopy, Gas/Liquid - chromatography techniques and mass-spectroscopy (GC/LC-MS) techniques have greatly aided in rapid identification of various metabolites. In fact NMR and GC-MS/LC-MS are the most widely used tools in metabolomics analysis (Chen et al., 2014; Coen et al., 2008; Grosch et al., 2013; Jackels et al., 2014; Nobakht et al., 2016; Scalbert et al., 2009; Smolinska et al., 2012; Sumner et al., 2003; Ulrich et al., 2008; Zekeya et al., 2014). NMR spectroscopy offers a readily usable technique, which has sensitivity at $\mathrm{nM}$ concentrations. In comparison, chromatography-MS coupled techniques shows sensitivity at $\mathrm{pM}$ concentrations and contains a huge number of organic molecules in their database resulting in greater ability to identify compounds (Grosch et al., 2013; Sumner et al., 2003). Due to the pros of both the techniques, many research groups have resorted to applying them for rapid and reliable assessments (Chen et al., 2014; Grosch et al., 2013; Ly et al., 2005).

Using a combination of GC-MS and NMR spectroscopy, we have identified various components by metabolic profiling that are present in mango seed kernels of raw (RaMK), intermediate (IrMK) and ripe (RiMK) states. As mentioned above, the IrMK is the unripe version that is used by the pickling industry. The data on metabolites present in different mango seed kernels will provide us an understanding on the positive effects of each kernel type and serve as an important biochemical repertoire for further studies and commercial interests in medicine and cosmetic industries.

\section{Materials and Methods}

\subsection{Sample Preparation}

All three types of seeds; raw, intermediate and ripe were dried. The hard shell was removed and the kernel was used for the intermediate and the ripe seeds only, while the raw seed did not contain any hard shell and was used as it is. The kernel was finely chopped and 13.5 grams of each type was treated separately in a conical flask containing 7.5:10:20 ml of water:iso-butanol:chloroform for organic phase extraction (Nzikou et al, 2010). The mixture 
was kept in dark for one week. The organic phase was separated from aqueous phase and was treated as described below prior to experimentation.

\subsection{Nucelar Magentic Resonance Spectroscopy}

Five $\mathrm{ml}$ of the samples were dried in a hot air oven maintained at $75^{\circ} \mathrm{C}$ for 2 days. To characterize hydrophilic and lipophilic extracts of the sample, the dried preparation was suspended in $0.5 \mathrm{ml} \mathrm{D}_{2} \mathrm{O}$ (deuterium oxide, 99.9\% D, Board of Radiation \& Isotope Technology) and $\mathrm{CDCl}_{3}(99.9 \% \mathrm{D}$ Aldrich Chemicals Company), respectively. All the samples were measured at $25^{\circ} \mathrm{C}$ on an AVANCE III HD Ascend $500 \mathrm{MHz}$ ((Bruker Biospin Switzerland) liquid state FT-NMR spectrometer coupled with a $5 \mathrm{~mm}$ BBFO probe, two rf-channels. All spectra were acquired at $298 \mathrm{~K}\left(25^{\circ} \mathrm{C}\right)$. The ${ }^{1} \mathrm{H}-\mathrm{NMR}$ spectra of Mango samples were recorded at constant temperature of $298 \mathrm{~K}\left(25^{\circ} \mathrm{C}\right)$ using the Carr-Purcell-Meiboom-Gill (CPMG) spin-echo pulse sequence (Carr and Purcell, 1954). The NMR lock signal was obtained by adding $\mathrm{D}_{2} \mathrm{O}$ and $\mathrm{CDCl}_{3}$. The acquisition parameters of ${ }^{1} \mathrm{H}$ included $10.2 \mathrm{~ms} 300$ pulse, 16 transients collected into $65 \mathrm{k}$ data points with a spectral width of $10000 \mathrm{~Hz}$, an acquisition time of $3.28 \mathrm{~s}$ and a relaxation delay of $1 \mathrm{~s}$. Prior to Fourier transformation, an exponential function corresponding to a line-broadening factor of $0.3 \mathrm{~Hz}$ was applied to the free induction decay (FID). The acquisition parameters of $1 \mathrm{D}^{13} \mathrm{C}$ spectrum included $1.1 \mathrm{~s} 90^{\circ}$ pulse, 1024 transients collected into $65 \mathrm{~K}$ data points with a spectral width of $29760 \mathrm{~Hz}$, an acquisition time of 3.28s and a relaxation delay of $2 \mathrm{~s}$ with ${ }^{1} \mathrm{H}$ decoupling using WALTZ-16 (Shaka et al., 1969). Prior to Fourier transformation, an exponential function corresponding to a line-broadening factor of $0.5 \mathrm{~Hz}$ was applied to the free induction decay (FID). ${ }^{1} \mathrm{H}-{ }^{13} \mathrm{C}$ HSQC spectra were recorded with the settings: 48 transients, $1024 \times 256$ points (F2 x F1) and spectral width of $4348 \mathrm{~Hz}$ and $20830 \mathrm{~Hz}$ for F2 and F1, respectively. All data sets were linear predicted and zero filled once in the indirect dimension before Fourier transformation and final processing. ${ }^{1} \mathrm{H}$ and ${ }^{13} \mathrm{C} \mathrm{NMR}$ spectra were calibrated with respect to water and chloroform peaks at 4.8 and $7.11 \mathrm{ppm}$, respectively. All raw time domain FIDs were extracted to frequency domain spectrum using system supported TopSpin NMR software (version3.5, Bruker Biospin Ltd.).

\subsection{Identification of Metabolites Based on NMR Spectroscopy}

NMR spectra contain information about the effective hydrophilic and hydrophobic metabolites present in the sample. The NMR chemical shift peak lists were submitted to the database, Biological Magnetic Resonance Data Bank (Ulrich et al., 2008) (BMRB-http://www.bmrb.wisc.edu/metabolomics/) metabolomics webserver. Metabolites corresponding to the submitted resonances were matched and identified using chemical shift of metabolites at BMRB database. The program enlisted a range of organic compounds that may occur in the sample that were indexed with a score. Higher score reflected greater peak match between recorded spectra and chemical shifts in database.

\subsection{Gas Chromatographic and Mass Spectrometric Analysis}

Mango sample $(1 \mathrm{mg})$ was dissolved in $1 \mathrm{~mL}$ of ethyl acetate and methanol $(1: 1 \mathrm{v} / \mathrm{v})$ at room temperature for 15 minutes followed by centrifugation $(3000 \mathrm{~g}, 10$ minutes $)$ at $4{ }^{\circ} \mathrm{C}$. Samples 
were analyzed with Shimadzu GC MS QP 2010 Ultra Gas chromatograph Mass Spectrometer. One $\mu \mathrm{L}$ sample was injected by auto sampler to Rtx 5 MS column capillary column coated with $5 \%$ phenyl cross-linked $95 \%$ dimethylpolysiloxane $(30 \mathrm{~m} \times 0.25 \mathrm{~mm}$ Id., $0.25 \mu \mathrm{m}$ film thickness). For GC/MS detection, an electron ionization system with ionizing energy of 70 $\mathrm{eV}$ was used. Helium gas (99.99\%) was used as the carrier gas.

Analyses were performed in the split mode with ratio 25 using helium gas carrier at 1.21 $\mathrm{mL} / \mathrm{min}$ flow by direct injection method with injection volume of $2 \mu \mathrm{L}$ using ion source temp $230^{\circ} \mathrm{C}$. Column temperature was maintained at $60^{\circ} \mathrm{C}$ for 10 minutes, then raised to $160^{\circ} \mathrm{C}$ at $10^{\circ} \mathrm{C} / \mathrm{min}$, held for 4 minutes then raised to $240^{\circ} \mathrm{C}$ at $8^{\circ} \mathrm{C} / \mathrm{min}$ and held for 6.0 minutes, and finally raised from 160 to $240^{\circ} \mathrm{C}$, over the range for data collection was 10-900Da. Mass spectra were taken at $70 \mathrm{eV}$ with $0.2 \mathrm{~s}$ scan interval.

\subsection{Metabolic Profiling Analysis Using GC-MS}

The peaks that were separated from GC-MS were identified by Postrum Analysis software (Shimadzu) using the mass spectral databases of the instrument. Peak assignments were made using dual criteria of mass spectral database and linear retention index match. Retention indices of the eluted compounds were calculated on the basis of the standard alkane mixture (C11-C18). By comparing the retention indices and unique mass spectra with the reference library matches and literature retention indices, assignments were derived and considered for only those compounds with a matching factor of $>50 \%$.

\section{Results and Discussion}

We analyzed the aqueous and organic phase of the extracts. Most of the compounds identified by both NMR (Figure 1 and 2) and GC-MS (Figure 3 and 4) showed a rich profile of fatty acids that accounts for more than $90 \%$ content in the RiMK (Kittiphoom, 2012). This is best appreciated from the NMR spectra in Figure 1, where one can observe intense chemical shift resonances for fatty acids in sample that was solubilized in $\mathrm{CDCl}_{3}$. The sample in $\mathrm{D}_{2} \mathrm{O}$ (Figure 1A) showed similar peaks but with far lower intensities along with chemical shifts for polar groups in the 2-4.5 ppm range of $1 \mathrm{D}{ }^{1} \mathrm{H}$ spectrum. In fact, when we compared the $1 \mathrm{D}$ ${ }^{13} \mathrm{C}$ spectra (Figure $1 \mathrm{~B}$ and $1 \mathrm{D}$ ), we noticed far greater signal intensities for the fatty acids and aromats in $\mathrm{CDCl}_{3}$ over $\mathrm{D}_{2} \mathrm{O}$ based sample, which is expected due to solubility of individual components. Furthermore, both the RiMK and IrMK samples shows a far diverse group of compounds that is readily visible in the $1 \mathrm{D}{ }^{1} \mathrm{H}$ spectra in $\mathrm{D}_{2} \mathrm{O}$ and $\mathrm{CDCl}_{3}$ (details of which are provided below). Similarly, when we performed GC-MS based analysis, we observed that all three samples were rich in FAs (retention time of 20-23 min, see figure 3), but the compound list for RaMK was far smaller than the other two. While fatty acids accounted for the major fraction in all tested seed kernel types, the remaining myriad organic molecules that were present in low quantities constituted phenolics and flavonoids that impart bitter taste and have medicinal values; building blocks such as sugars, amino acids, nucleotides and vitamins; and silicaceous organics were found in seed coatings (Appendix, Tables 1 and 2). 
A

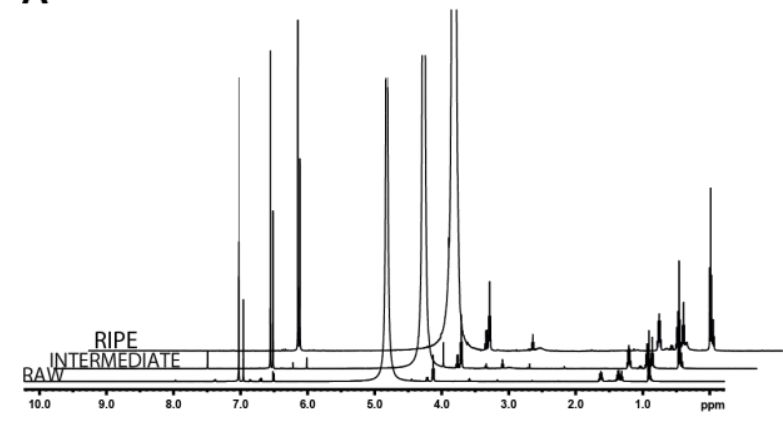

B
C

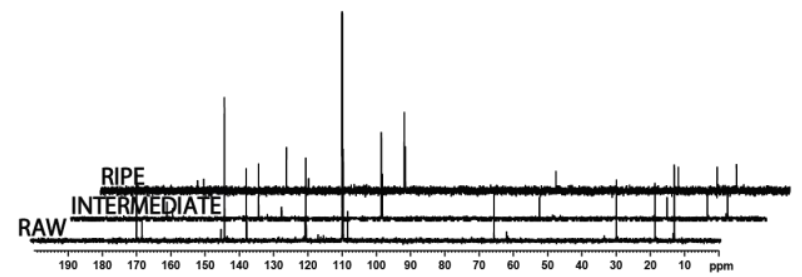

D

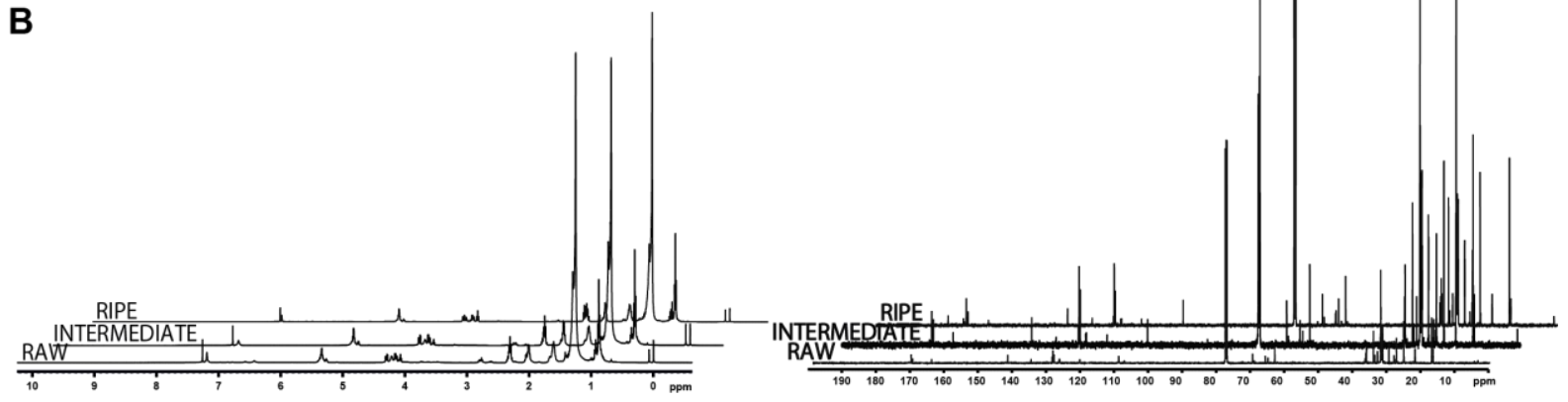

Figure 1. 1D ${ }^{1} \mathrm{H}$ (top) and ${ }^{13} \mathrm{C}$ spectra (bottom) for mango kernel samples in $\mathrm{D}_{2} \mathrm{O}$ (left) and $\mathrm{CDCl}_{3}$ (right).

A

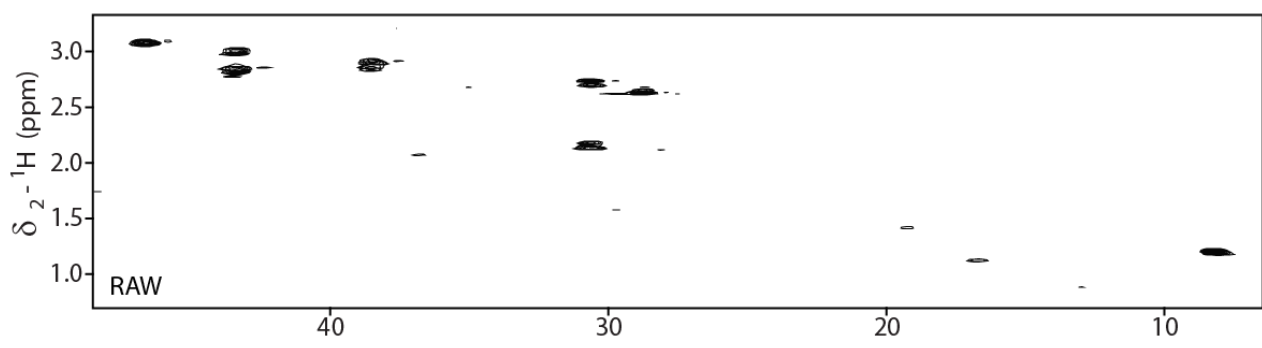

C

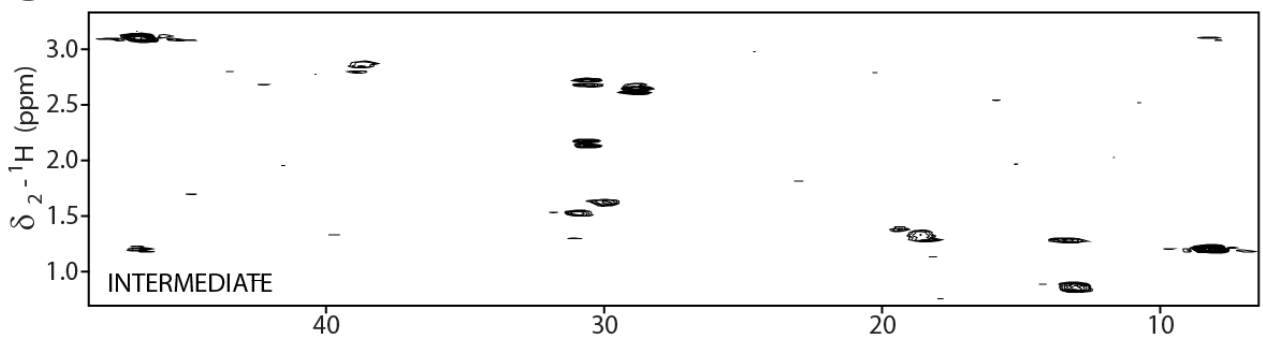

$\mathbf{E}$

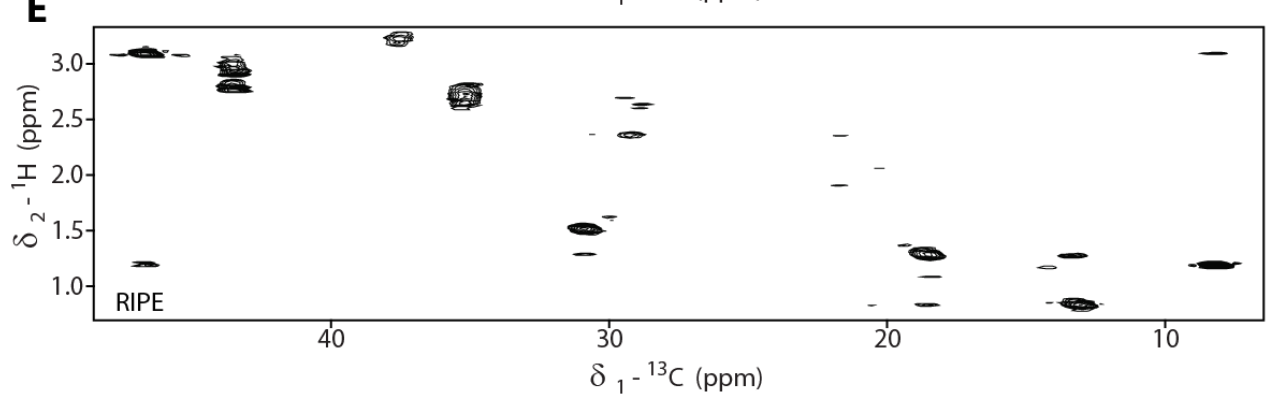

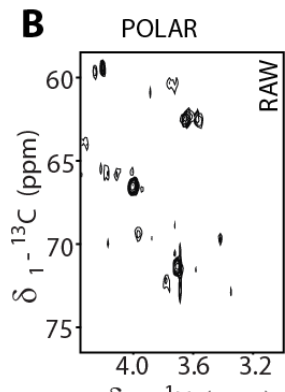

$\delta_{2}-{ }^{1} \mathrm{H}(\mathrm{ppm})$
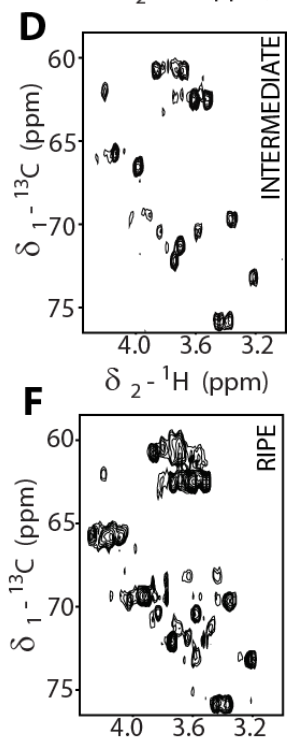

$\delta_{2^{-}{ }^{1} \mathrm{H}(\mathrm{ppm})}$

Figure 2. 2D ${ }^{1} \mathrm{H}_{-}{ }^{13} \mathrm{C}$ HSQC of the three stages of mango kernel in $\mathrm{D}_{2} \mathrm{O}$. 
Comparison of metabolomics results between the two analytical techniques, we noticed few attributes; firstly, there were a handful of absolute compound matches between the two techniques, which was restricted to FAs such as stearic acid, palmitic acid and others. Secondly, albeit few absolute matches, the compounds identified by both techniques, NMR (appendix table1) and MS (appendix table2) belonged to similar functional groups. In all tested samples, based on GC-MS data (Figure 3 and 4), we did not notice the presence of molecules that are intrinsic for glucose, amino acid metabolism and TCA pathways. The NMR experiments on the other hand revealed the probable presence of these compounds but with low scores. This discrepancy may arise due to the number of molecules deposited in the database (Scalbert et al., 2009; Sumner et al., 2003). Perhaps, it may also reflect on the sampling and sensitivity of the technique itself, with GC-MS being a 1000 fold more sensitive than NMR spectroscopy (Grosch et al., 2013; Sumner et al., 2003) resulting in matches with greater accuracy.

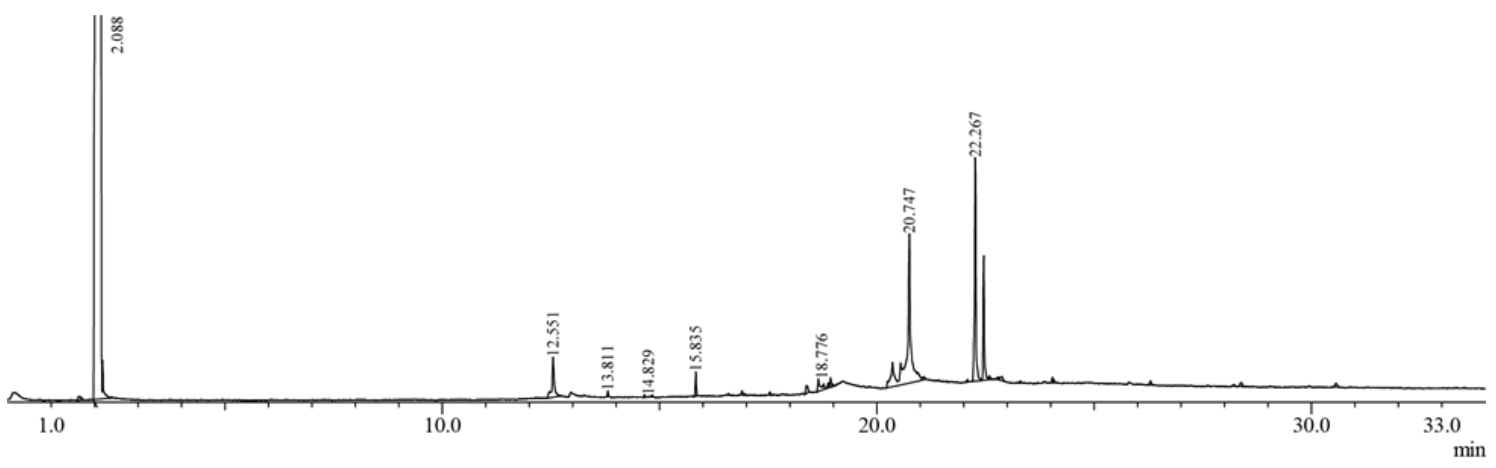

Figure 3. Gas chromatogram of analytes from the IM mango kernel sample. The individual fractions were subject to Mass spectroscopy (see Figure 4).

From the NMR experiments (appendix table1) we identified a variety of organic molecules in the IrMK and RiMK. The RaMK showed precursors for amino acid and lipid synthesis albeit with low scores. On the other hand the RiMK showed the presence of FAs such as decanoic acid, dodecanoic acid, glyceryl tridecanoate, myristic acid, palmitoleic acid and stearic acid; which is sought by the cosmetic industry and agrees well with previously reported data (Shobana and Rajalakshmi 2010). In addition to FAs, we noticed presence of building blocks like amino acids, sugars and nucleotides albeit with a lot lower score. In stark contrast, we observed amino acids, fatty acids and many of their precursors in the sample of IrMK with intermediate scores. These findings clearly illustrate that the RaMK contains few precursor metabolites, the IrMK showed a mixed presence of precursors and metabolites at the end of the cycle, while the RiMK is rich in various fatty acids.

Simultaneously, we analysed the GC-MS data to understand the contents of the kernel. As GC-MS is 1000-fold more sensitive than NMR we expected to see a diverse array of molecules. Indeed, we observed a wide variety of phytocomponents that have plenty of interesting medicinal properties (Table 1). In short, all three samples were rich in fatty acids and aromats, which is listed in table 2 and few interesting molecules have been described in section below. In the sample of RaMK we identified a couple of FAs and aromatic 


\section{MlMacrothink}

Journal of Agricultural Studies

ISSN 2166-0379

2017, Vol. 5, No. 1

compounds such as kojic acid (Bentley, 2006), which is commonly employed in cosmetics and mycotoxins; benzentriols (Kocacaliskan et al., 2006; Tomás-Barberán et al., 1990; Zekeya et al., 2014), barbitals (Lopez-Munoz et al., 2005) and aromatic-fatty acids, which imparts bitterness and antimicrobial properties; hence it used in traditional Indian ayurvedic medicine, especially related to gastric problems. In the RiMK, we largely observed a variety of FAs and esters along with a few aromats. RiMK showed presence of FAs similar to the NMR experiments such as stearic acid, palmitic acid, oleic acid, etc; furthermore, it also contains a wide variety of esters that imparts fragrance to the extracted butter. These findings highlight the reason for mango butter being a highly sought product in food and cosmetic industry. In the IrMK, we observed a larger diversity of fatty and organic acids in comparison to the RiMK. The aromatic content of IrMK was also substantially higher as it contained antimicrobials derivatives from barbitals (Lopez-Munoz et al., 2005), phtalic acid (Srinivasan et al., 2009), benzofuranone (Chiu et al., 2014; Ly et al., 2005) etc. IrMK encompasses properties of both RaMK and RiMK in terms of its antimicrobial properties (although the identified compounds were not the same) and biochemicals for cosmetic industries. In addition to these, we have enlisted (Table 1) some of the industrial applications of the various secondary metabolites in the above preparations.
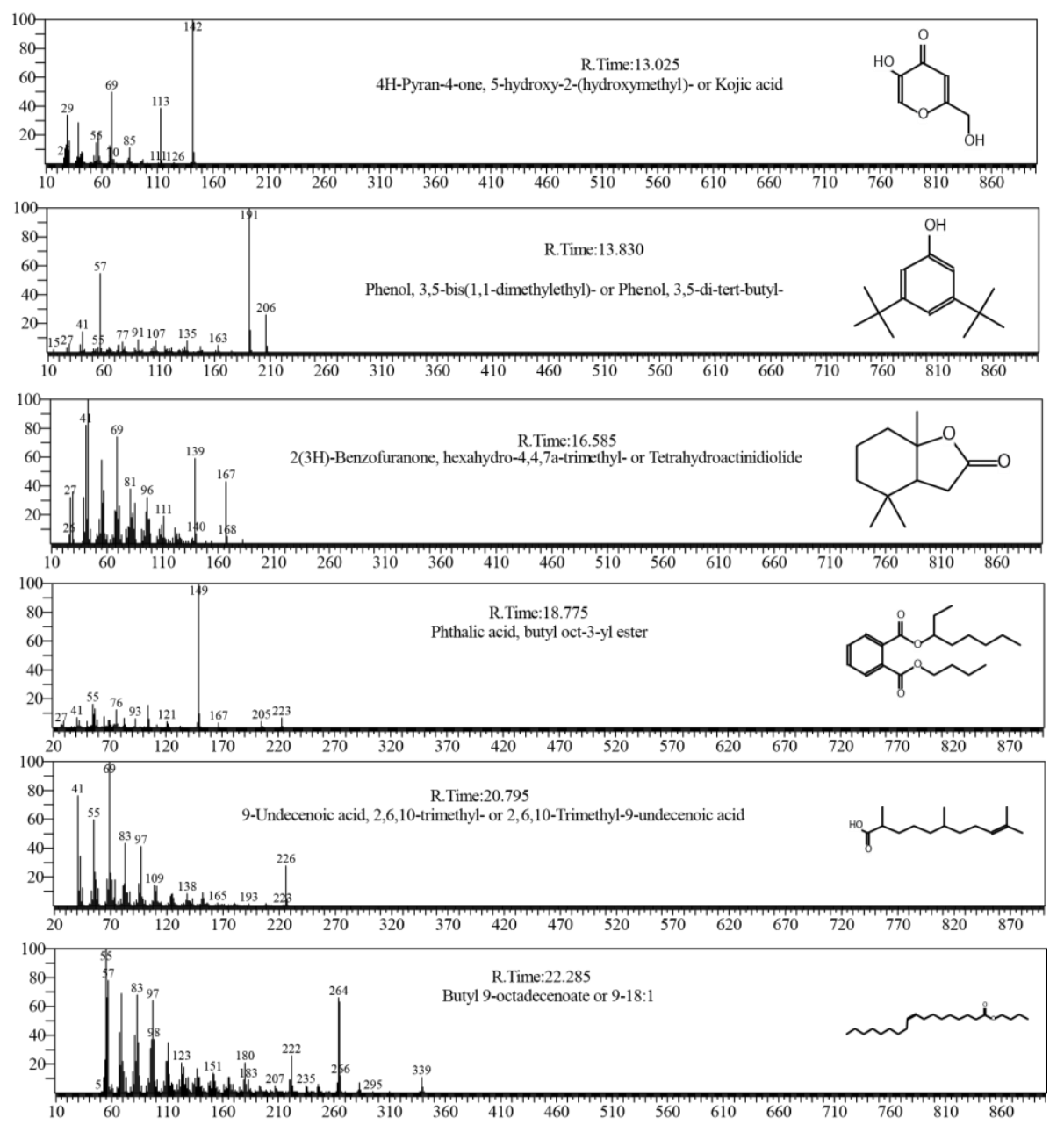

Figure 4. MS spectra of diverse group of compounds identified from the various fractions of gas chromatogram for IrMK (see Table 1 and appendix table2). 
Table 1. Use of various secondary metabolites from different stages of mango kernel extract

\begin{tabular}{|c|c|}
\hline Product & pplications \\
\hline $\begin{array}{l}\text { Raw mango kernel: } \\
\text { 1. } \text { n-Eicosanoic acid; Stearic acid; Tetradecanoic acid } \\
\text { anhydride; (3E)-3-Pentadecen-2-oL } \\
\text { 2. (3Z)-3-Butyl-3-octen-2-one; } \\
\text { 2,2-Dimethyl-5-(3-methyl-2-oxiranyl) cyclohexanone; } \\
\text { 3-(Hydroxymethyl)-6-isopropyl-2-cyclohexen-1-one } \\
\text { 3. 1,2,3-Benzenetriol; 1,2,4-Benzenetriol; Benzoic acid, } \\
\text { 3,4,5-trihydroxy-, butyl ester; 3'-Hydroxyquinalbarbitone; } \\
\text { 5-Methyl-1H-pyrazole-3-carboxylic acid }\end{array}$ & $\begin{array}{l}\text { Emulsifiers for food, soap } \\
\text { and cosmetic industry } \\
\text { Odorants } \\
\text { Medicine and } \\
\text { pharmacology }\end{array}$ \\
\hline $\begin{array}{l}\text { Intermediate mango kernel: } \\
\text { 1. 2,3-Bis[(9E)-9-octadecenoyloxy]propyl } \\
\text { (9E)-9-octadecenoate; Pentadecyl acrylate; Tetradecanoic } \\
\text { acid, propyl ester; Heptadecafluorononanoic acid; } \\
\text { octadecyl ester Nonadecyl } \\
\text { 2,2,3,3,4,4,4-heptafluorobutanoate; 1-Propyldecyl } \\
\text { methoxyacetate }\end{array}$ & $\begin{array}{l}\text { Odorants and emulsifiers } \\
\text { for food and cosmetic } \\
\text { industry }\end{array}$ \\
\hline $\begin{array}{l}\text { 2. Tetradecanoic acid, butyl ester; 3-Ethyl-5 Docosan-1-ol; } \\
\text { 2,6,10-Trimethyldodecane 2,3-dihydroxypropyl ester; } \\
\text { Pentadecyl acrylate; 14-Bromopentadecanoic acid; } \\
\text { Octadec-9-enoic acid; Octadeca-1-ene; }\end{array}$ & $\begin{array}{l}\text { Emulsifiers, lubricants, } \\
\text { surfactants for food, soap } \\
\text { and cosmetic industry }\end{array}$ \\
\hline $\begin{array}{l}\text { 1-Hydroxytridecane } \\
\text { 3. (7E)-7-Methyl-7-heptadecene; 2-Oxooctadecanoic acid; } \\
\text { (9Z)-9-Tricosene; Phthalic acid, butyl oct-3-yl ester; } \\
\text { Phthalic acid, butyl oct-3-yl ester; cyclobarbital; } \\
\text { 2,6,10-Trimethyl-9-undecenoic acid } \\
\text { 1-(+)-Ascorbic acid 2,6-dihexadecanoate ; } \\
\text { 2,3-Dihydroflavone; } \\
\text { 1-Methoxy-2-[1-(4-methoxyphenyl)-1-methylethyl]benze } \\
\text { ne; 5-Hydroxy-2-(hydroxymethyl)-4-pyrone; } \\
\text { 4,4,7a-Trimethylhexahydro-1-benzofuran-2(3H)-one }\end{array}$ & $\begin{array}{ll}\text { Medicine } & \text { and } \\
\text { pharmacology } & \end{array}$ \\
\hline $\begin{array}{l}\text { Ripe mango kernel: } \\
\text { 1. Nonadec-1-ene; Stearic acid; cis-Oleic Acid; Palmitic } \\
\text { acid; 2,3-Dihydroxypropyl (9E)-9-octadecenoate; } \\
\text { 9-Octadecenoic acid; n-Pentadecanoic acid ;n-Eicosanoic } \\
\text { acid; n-Octadecanol } \\
\text { cis-9-Hexadecenoic acid; isobutyl hexadecanoate. } \\
\text { 2. 1-(+)-Ascorbic acid 2,6-dihexadecanoate; 2,6-Bis(tert- } \\
\text { butyl)phenol; 2,4-Di-tert-butylphenol; } \\
\text { 2,2-Bis(3-methyl-4-hydroxyphenyl)propane; } \\
\text { 2-Hydroxycyclopentadecanone. }\end{array}$ & $\begin{array}{l}\text { Emulsifiers for food, soap } \\
\text { and cosmetic industry } \\
\text { Odorants } \\
\text { Antioxidants and odorants }\end{array}$ \\
\hline
\end{tabular}




\section{Conclusion}

India is the largest producer of mangoes globally accounting for more than $50 \%$ of the production amounting up to 23 million tonnes $\mathrm{Kg}$ per annum (Ministry of Agriculture, Government of India (2013); Srikanth et al. 2015). As the mango kernel accounts for nearly $40-65 \%$ of the weight and an extraction efficiency of $10 \%$, indicates that at least 2.3 million tonnes $\mathrm{Kg}$ of mango butter can be readily extracted. This work highlights that the kernels obtained from intermediate stage mango is rich in biochemical in comparison to the ripe and raw versions. Herein, we show that the reason raw and intermediate mangoes are used for culinary purposes and ayurvedic medicine applications is due to the presence of aromatic compounds belonging to phenolics (Akagawa and Suyama, 2001; Zekeya et al., 2014) and flavonoids (Zekeya et al., 2014) that show antimicrobial properties and may also add to the flavour. On the other hand, we have shown that the RiMK contains very few aromats but a variety of FAs akin similar reports by other groups, which is required by the cosmetic industry. But IrMK also contains these different classes of FAs albeit $\sim 3$ fold lower than its ripe counterpart by comparing the gas chromatograms.

Although, the overall fatty acid content in the IrMK butter is lower than RiMK, it is rich in anti-oxidative and antimicrobials. Similar to RiMK butter extraction, IrMK butter can be readily extracted by using press filtration, organic solvent extraction (Gunstone, 2007; Nzikou et al, 2010; Kittiphoom and Sutasinee 2013) or distilling with supercritical $\mathrm{CO}_{2}$ (Akanda et al. 2015). Like RiMK butter, IrMK butter will also find value in confectionaries (Ashoush and Gadallah, 2011; Pereira et al., 2011) and cosmetic industry (Kaphueakngam et al, 2009) due to similar content. The dried stone that is left behind after the entire process can be used either as mulch, cattle feed (FAO 2013; UNIDO) or for cultivation of mushrooms (Stamets, 1993) thereby reducing environmental contamination and at the same time adding value to the product.

Interestingly, the intermediate stage kernel is used by the pickle industry, where the seed is obtained as a by-product and is usually discarded. An average medium-scale pickle factory in India can generate up to $500 \mathrm{Kg}$ of mango stone/day for a period of three months (March-May). If one were to assume loss in weight due to stone and extraction process yielding only $10 \%$ butter, it still offers a lucrative $50 \mathrm{Kg}$ of mango butter daily, which sells at $\sim 400 \mathrm{INR} / \mathrm{Kg}$ (5 Euros/ $\mathrm{Kg}$ ). This results in a total of 4.5 tonnes $\mathrm{Kg}$ of mango butter (1.8 million INR (200,000 Euros)) during the three months pickling season. According to the reports by $\mathrm{UN}$ and FAO, the potential of commercializing mango butter is huge and greatly untapped. It is thus pertinent that one highlights the biochemical composition of IrMK to the industry on the valued product thereby also reducing biological waste.

\section{Acknowledgement}

DUU thank the support of Savitribai Phule Pune University; JT, VM, NC and AAC for Vijay chemicals and Neeti Developers.

\section{References}

Akagawa, M., \& Suyama, K. (2001). Amine oxidase-like activity of polyphenols. Mechanism 
and properties. European Journal of Biochemistry, 268, 1953-1963. https://doi.org/10.1046/j.1432-1327.2001.02068.x

Akanda, M. J. H., Sarker, M. Z. I., Norulaini, N. Ferdosh, S., M. Rahman, M. M., \& Omar, A. K. M. (2015). Optimization of supercritical carbon dioxide extraction parameters of cocoa butter analogy fat from mango seed kernel oil using response surface methodology. Journal of Food Science and Technology, 52, 319-326. https://doi.org/10.1007/s13197-013-0979-x

Alok, P., Keerthana, V., Kumar, J. C., Ratan, K., \& Chand, A. D. (2013). Antibacterial Property of Two Different Varieties of Indian Mango (Mangifera indica) Kernel Extracts at Various Concentrations against some Human Pathogenic Bacterial strains. International Research Journal of Biological Sciences, 2, 28-32.

Ashoush, I. S, \& Gadallah, M. G. E. (2011). Utilization of Mango Peels and Seed Kernels Powders as Sources of Phytochemicals in Biscuit. World Journal of Dairy \& Food Sciences, $6,35-42$.

Bentley, R. (2006). From miso, sake and shoyu to cosmetics: a century of science for kojic acid. Natural Product Report, 23, 1046-1062. https://doi.org/10.1039/b603758p

Carr, H. Y., \& Purcell, E. M. (1954). Effects of Diffusion on Free Precession in Nuclear Magnetic Resonance Experiments. Physical Review, 94, 630-638. https://doi.org/10.1103/PhysRev.94.630

Chen, J. J., Liu, Z., Fan, S. H., Yang, D. Y., Zheng, P., Shao, W. H., Qi, Z. G., Xu, X. J., Li, Q., $\mathrm{Mu}$, J., Yang, Y. T., \& Xie, P. (2014). Combined application of NMR- and GC-MS-based metabonomics yields a superior urinary biomarker panel for bipolar disorder. Science Report, 4, 5855-5861. https://doi.org/10.1038/srep05855

Chiu, C. F., Su, C. Y., \& Lee, E. (2014). Benzofuranone derivatives and application of the same. Patent US20120238677.

Coen, M., Holmes, E., Lindon, J. C., \& Nicholson, J. K. (2008). NMR-Based Metabolic Profiling and Metabonomic Approaches to Problems in Molecular Toxicology. Chemical Research in Toxicology, 21, 9-27. https://doi.org/10.1021/tx700335d

FAO - Food and Agricultural Organization. (2002). MANGO: Post Harvest Operations http://www.fao.org/3/a-i3273e.pdf

FAO - Food and Agricultural Organization. (2013). Utilization of fruit and vegetable wastes as livestock feed and as substrates for generation of other value added products. http://www.fao.org/3/a-av008e.pdf

Gil, A. M., Duarte, I. F., Delgadillo, I., Colquhoun, I. J., Casuscelli, F., Humpfer, E., \& Spraul, M. (2000). Study of the compositional changes of mango during ripening by use of nuclear magnetic resonance spectroscopy. Journal of Agriculture Food Chemistry, 48, 1524-1536. https://doi.org/10.1021/jf9911287

Grosch, S., Monakhova, Y. B., Kuballa, T., Ruge, W., Kimmich, R., \& Lachenmeier, D. W. 
(2013). Comparison of GC/MS and NMR for quantification of methyleugenol in food. European Food Research Technology, 236, 267-275.

https://doi.org/10.1007/s00217-012-1879-4

Gunstone, F.J. H., \& A. Dijkstra (2007). The Lipid Handbook. 180.

Jackels, S. C., Marshall, E. E., Omaiye, A. G., Gianan, R. L., Lee, F. T., \& Jackels, C. F. (2014). GCMS investigation of volatile compounds in green coffee affected by potato taste defect and the Antestia bug. Journal of Agriculture Food Chemistry, 62, 10222-10229. https://doi.org/10.1021/jf5034416

Kaphueakngam, P., Flood, A., \& Sonwai, S. (2009). Production of cocoa butter equivalent from mango seed almond fat and palm oil mid-fraction. Asian Journal of Food and Agro-Industry, 2, 441-447

Khakimov, B., Mongi, R. J., Sorensen, K. M., Ndabikunze, B. K., Chove, B. E., \& Engelsen, S. B. (2016). A comprehensive and comparative GC-MS metabolomics study of non-volatiles in Tanzanian grown mango, pineapple, jackfruit, baobab and tamarind fruits. Food Chemistry, 213, 691-699. https://doi.org/10.1016/j.foodchem.2016.07.005

Kittiphoom, S. (2012). Utilization of Mango seed. International Food Research Journal, 19, 1325-1335.

Kittiphoom, S., \& Sutasinee, S. (2013). Mango seed kernel oil and its physicochemical properties. International Food Research Journal, 20, 1145-1149.

Kocacaliskan, I., Talan, I., \& Terzi, I. (2006). Antimicrobial activity of catechol and pyrogallol as allelochemicals. Zeitschrift für Naturforschung, $C$ 61, 639-642. https://doi.org/10.1515/znc-2006-9-1004

Leake, C. D. (1974). Review of reviews. Annual Review of Pharmacology and Toxicology, 18, 581-588. https://doi.org/10.1146/annurev.pa.14.040174.002513

Lopez-Munoz, F., Ucha-Udabe, R., \& Alamo, C. (2005). The history of barbiturates a century after their clinical introduction. Neuropsychiatr Dis Treat, 1, 329-343.

Ly, T. N., Hazama, C., Shimoyamada, M., Ando, H., Kato, K., \& Yamauchi, R. (2005). Antioxidative compounds from the outer scales of onion. J Agric Food Chem, 53, 8183-8189. https://doi.org/10.1021/jf051264d

Ministry of Agriculture, Government of India (2013) Post Harvest profile of mango. http://agmarknet.gov.in/Others/preface-mango.pdf

Nobakht, B. F., Aliannejad, R., Rezaei-Tavirani, M., Arefi Oskouie, A., Naseri, M. T., Parastar, H., Aliakbarzadeh, G., Fathi, F., \& Taheri, S. (2016). NMR- and GC/MS-based metabolomics of sulfur mustard exposed individuals: a pilot study. Biomarkers, 17, 1-11. https://doi.org/10.1080/1354750X.2016.1203995

Nzikou, J.M. A. K., L. Matos, B. Loumouamou, N.P.G. Pambou-Tobi, C.B. Ndangui, A. A. Abena, Th. Silou, J. Scher and S. Desobry (2010). Extraction and Characteristics of Seed 


\section{Macrothink}

Journal of Agricultural Studies

ISSN 2166-0379

2017, Vol. 5, No. 1

Kernel Oil from Mango (Mangifera indica). Research Journal of Environmental and Earth Sciences, 2, 31-35.

Pereira, A. L. F., Vidal, T. F., Teixeira, M. C., Oliveira, P. F. d., Pompeu, R. C. F. F., Vieira, M. M. M., \& Zapata, J. F. F. (2011). Antioxidant effect of mango seed extract and butylated hydroxytoluene in bologna-type mortadella during storage. Ciência e Tecnologia de Alimentos, 31, 135-140. https://doi.org/10.1590/S0101-20612011000100019

Scalbert, A., Brennan, L., Fiehn, O., Hankemeier, T., Kristal, B. S., van Ommen, B., Pujos-Guillot, E., Verheij, E., Wishart, D., \& Wopereis, S. (2009). Mass-spectrometry-based metabolomics: limitations and recommendations for future progress with particular focus on nutrition research. Metabolomics, 5, 435-458. https://doi.org/10.1007/s11306-009-0168-0

Shaka, A. J., Keeler, J., \& Freeman, R. (1969). Evaluation of a new broadband decoupling sequence: WALTZ-16. Journal of Magnetic Resonance, 53, 313-340.

Shobana, V., \& Rajalakshmi, K. (2010). Quantitative Analysis Of Primary Metabolites In Mangifera indica (unripe mango). Rasayan Journal of Chemistry, 3, 25-29.

Smolinska, A., Blanchet, L., Buydens, L. M., \& Wijmenga, S. S. (2012). NMR and pattern recognition methods in metabolomics: from data acquisition to biomarker discovery: a review. Analytica Chimica Acta, 750, 82-97. https://doi.org/10.1016/j.aca.2012.05.049

Srinivasan, G. V., Sharanappa, P., Leela, N. K., Sadashiva, C. T., \& Vijayan, K. K. (2009). Chemical composition and antimicrobial activity of the essential oil of Leea indica (Burm. f.) Merr. flowers. Natural Product Radiance, 8, 488-493.

Stamets, P. (1993). Growing Gourmet and Medicinal Mushrooms 586.

Srikanth, H. S., Venkata Reddy, T. N., Prasanna Kumar, P. S., \& Ranganath, G. (2015). Study on arrival pattern of mango in APMC and direction of trade from Srinivasapura taluka of Kolar district. International Journal of Commerce and Business Management, 8, 75-80. https://doi.org/10.15740/HAS/IJCBM/8.1/75-80

Sumner, L. W., Mendes, P., \& Dixon, R. A. (2003). Plant metabolomics: large-scale phytochemistry in the functional genomics era. Phytochemistry, 62, 817-836. https://doi.org/10.1016/S0031-9422(02)00708-2

Tomás-Barberán, F., Iniesta-Sanmartín, E., Tomás-Lorente, F., \& Rumbero, A. (1990). Antimicrobial phenolic compounds from three Spanish Helichrysum species. Phytochemistry 29, 1093-1095. https://doi.org/10.1016/0031-9422(90)85410-H

Ulrich, E. L., Akutsu, H., Doreleijers, J. F., Harano, Y., Ioannidis, Y. E., Lin, J., Livny, M., Mading, S., Maziuk, D., Miller, Z., Nakatani, E., Schulte, C. F., Tolmie, D. E., Kent Wenger, R., Yao, H., \& Markley, J. L. (2008). BioMagResBank. Nucleic Acids Research 36, D402-408.

UNIDO - United Nations Industrial development Organization http://www.unido.org/fileadmin/import/32068_35FoodWastes 


\section{Macrothink}

Journal of Agricultural Studies

ISSN 2166-0379 2017, Vol. 5, No. 1

Zekeya, N., Chacha, M., Shahada, F., \& Kidukuli, A. (2014). Analysis of phytochemical composition of Bersama abyssinica by gas chromatography - mass spectrometry. Journal of Pharmacognosy and Phytochemistry, 3, 246-252.

\section{Copyright Disclaimer}

Copyright for this article is retained by the author(s), with first publication rights granted to the journal.

This is an open-access article distributed under the terms and conditions of the Creative Commons Attribution license (http://creativecommons.org/licenses/by/4.0/). 